\title{
Surrogates and Empty Intentions: Husserl's “On the Logic of Signs" as the Blueprint for his First Logical Investigation
}

\author{
Thomas Byrne $^{1}$ (D)
}

Published online: 24 March 2017

(C) Springer Science+Business Media Dordrecht 2017

\begin{abstract}
This paper accomplishes two tasks. First, I examine in detail Edmund Husserl's earliest philosophy of surrogates, as it is found in his 1890 "On the Logic of Signs (Semiotic)". I analyze his psychological and logical investigations of surrogates, where the former is concerned with explaining how these signs function and the latter with how they do so reliably. His differentiation of surrogates on the basis of their genetic origins and degrees of necessity is discussed. Second, the historical importance of this text is disclosed by showing how Semiotic serves as both the inspiration for, and the foil to, Husserl's 1901 First Logical Investigation. Husserl not only adopts the idea that linguistic signs can function via association, but also maintains that such signs can motivate me to execute one of two experiences. The key difference between the texts is that Husserl abandons his theory of surrogates in 1901, instead holding that I can experience absent objects by means of empty intentions. The reasons why Husserl found it necessary to transform this tenet of his philosophy are discussed at length.
\end{abstract}

\section{Introduction}

In his earliest writings, Husserl manifests great distress at the fact that it is not yet properly understood how certain concepts or objects, which are not given to me inperson or "authentically" presented, can still be dealt with and known, that is, "inauthentically" presented by means of signs. In his 1891 Philosophy of Arithmetic

Thomas Byrne

T.byrne3@gmail.com; Thomas.byrneiii@kuleuven.be

1 Husserl-Archives: Centre for Phenomenology and Continental Philosophy, KU Leuven, Kardinaal Mercierplein 2 - box 3200, 3000 Leuven, Belgium 
(Hua XII/2003; hereafter PA), ${ }^{1}$ Husserl asserts that this is most troubling for mathematics since it remains unclear how number signs inauthentically present their conceptual and natural numbers; but he is also perplexed by how the presentation of logical and linguistic signs can motivate inauthentic presentations. Regardless of which field he seeks to understand, the early Husserl's resolution of this difficulty is the same: A sign inauthentically presents its signified object by serving as its replacement (Ersatz) or surrogate (Surrogat), these two being equivalent. Even though the signitive operation of replacement is the keystone of his philosophy, Husserl often simply asserts that this process is responsible for inauthentic presentation without further elaboration. ${ }^{2}$ It appears that he wished for that term to be understood in its everyday sense; the sign replaces the object, it is its surrogate. The contemporary literature, following Husserl's lead, has also frequently taken this notion at face value.

Yet, Husserl did recognize surrogation as a highly complex and deeply problematic concept. In an attempt to clarify this idea, in a text from $1890,{ }^{3}$ entitled "On the Logic of Signs (Semiotic)" (hereafter LZ), he dedicates great efforts to describing the mental mechanisms by means of which replacement can occur and to detailing the different species and genera of surrogates. Of note is that Husserl is primarily focused, in contrast to the study in PA, on linguistic and logical signs. Husserl wrote LZ because he recognized that one could not understand his other views without first clearly grasping the notion of surrogation; thus it is surprising to learn that his conclusions there have been rarely discussed in the literature. $^{4}$

For these reasons, the first goal of this article is to provide a focused study of Husserl's analysis of surrogates in LZ. This task is accomplished in two stages. In

\footnotetext{
${ }^{1}$ While all translations are mine, I will provide references to the corresponding English translation where available, following a slash after the Hua page number. Quotes from the Logical Investigations always come from the First Edition.

2 The reader can validate the fact that Husserl, in PA, is content to employ the terms, "Surrogat", "surrogieren", and "ersetzen" as they are ordinarily understood by looking at any of the twenty-one times he uses them in the context of describing how a sign replaces its signified. To provide one example, when Husserl first uses the term "Surrogat", he provides no clarification but merely postulates that operation. He writes, "Accordingly, the symbolic presentation serves us as a provisional representation, and, in cases where the authentic presentation is inaccessible, even as a enduring one" (Hua XII, p. 194/ 206).

${ }^{3}$ If one assumes Ierna's dating (2005, pp. 36-40), Husserl wrote LZ immediately after composing his letter to Carl Stumpf, within which he admitted that the project of his forthcoming Philosophy of Arithmetic, to ground mathematics in the concept of number, was fundamentally misguided (Hua XII, pp. 244-251/1994c, pp. 12-19). In contrast, if one follows Willard's (1980, pp. 111-116) or Hopkins' (2002, pp. 60-71) interpretations, he composed LZ even prior to the correspondence with Stumpf! In either case, Husserl's focus on logic and language in LZ demonstrates that his philosophy was already undergoing great shifts at a much earlier date than has been accounted for in the literature. For example, Robin Rollinger writes that it was only subsequent to Husserl's 1893 attempt to provide a philosophy of space that he, "became more and more concerned with logic instead of the more restricted area of arithmetic and geometry" (1999, p. 44). For another case, Ierna asserts that Husserl's criticism of Brentano's theory of judgment, found in his 1896 Logic lectures, constitutes the decisive turning point in his work toward a focus on logical analyses (2008, pp. 58-60).

${ }^{4}$ To the best of my knowledge, there are six articles that discuss the tenets of LZ in some detail. These are: D’Angelo (2013), Ierna (2003), Majolino (2010, 2012), Zuh (2008, 2012).
} 
the first section, I examine Husserl's descriptions of motivating linguistic signs, which often kick-start the replacement process. I then engage in an extensive investigation of Husserl's psychological and logical analyses of the operation of surrogates (2.1), and his differentiation of those replacement signs (2.2).

The third section cashes out the close study of LZ. It reveals why this comparatively short text is of further historical and philosophical importance for Husserl scholarship, as it serves as the groundwork and inspiration for Husserl's later analyses. It will be demonstrated how Husserl's descriptions of signitive experience in 1890 function as a catalyst for his discussions of meaningful expressions in his 1901 First Logical Investigation (Hua XIX/1970; hereafter LU). Indeed, when one begins to read that Investigation, many of the conclusions Husserl reaches appear to float in thin air, since he seems to be arguing against an opponent of whom the reader has no knowledge. It is by placing LU within the context of LZ, as its progenitor, that Husserl's nuanced and often perplexing claims presented in the former can be clarified as his attempt to work from and against the latter.

\section{Associatively Motivating Signs}

Husserl's analysis of motivating linguistic signs in LZ discloses one of the ways in which surrogates can become presented to consciousness, thereby paving the way for his psychological and logical examinations of the latter. The grounding tenet of this study is that when I am presented with a linguistic sign, two different mental operations can occur: the sign can associatively motivate me either to execute an authentic presentation of the signified or to present a surrogate for it, that is, to perform an inauthentic presentation. ${ }^{5}$ Both shifts occur via the two steps of association: linking and reawakening. ${ }^{6}$

To clarify these two cases, I use the simple example of someone giving me a blue coffee cup as a gift. ${ }^{7}$ When receiving it, I experienced the authentic presentation of the cup: I see it, in person, in robust detail. Husserl explains that to every authentic presentation, there can become associatively tied a manifold of other presentations (Hua XII, p. 353/1994d, pp. 32-33). For example, the cup may have a unique image

\footnotetext{
5 In LZ, Husserl also examines two different ways linguistic signs can motivate me to execute authentic or inauthentic presentations. On the one hand, there are external signs, which refer to but do not characterize or describe their objects (Hua XII, p. 341/1994d, p. 21). They passively impel me to a oneray, direct, and immediate awareness of the object. On the other, conceptual signs motivate me to execute presentations that relate signified characteristics or objects (Hua XII, pp. 342-344/1994d, pp. 22-23).

6 In both LZ (Hua XII, pp. 341-342/1994d, pp. 21-22) and PA (Hua XII, pp. 193-194/205-207) Husserl states, but never clarifies, that linguistic signs can serve as surrogates. My future research is dedicated to demonstrating why Husserl cannot maintain this doctrine in either text, as it would, at best, be inconsistent with, and at worst, contradict almost all of what he says about the replacement operation in LZ and PA.

7 For a fully correct appreciation of this case, one must assume that I had not heard or thought about cups, nor had I seen any images of them before I received this gift. This is to say that I never formed an inauthentic presentation of a cup prior to my perception (authentic presentation) of this one. Cases where I do construct an inauthentic presentation of an intentional object before having an authentic presentation of it, which Husserl terms "genetically primary surrogates" (Hua XII, p. 354/1994d, p. 33), will be discussed in Sect. 2.2.
} 
of the Ouroboros imprinted on it. This characteristic of the cup is then associatively linked to the cup itself. Importantly, Husserl asserts that the presentation of the voiced and written linguistic sign, "cup", can also become (and in this case, we assume, is) associatively tied with the perception of the cup (Hua XII, p. 353/1994d, p. 32).

At a later point in time, when I am talking with a friend on the phone about that gift while also having the cup on the table before me, she may ask, "What color is the cup?" Husserl states that I can answer this question because the previously instituted associative link between the linguistic sign, "cup", and the presentation of the cup is reawakened. When I hear that word, I am passively impelled or associatively motivated to authentically present the cup that is before me and recognize it as that which corresponds to the sign. It is taken as the sign's meaning; I see it as the object that my friend is inquiring about. By doing so, I am able to see, know, and state to her, "The cup is blue".

Not only linguistic signs can perform this motivational and signitive operation. Any object or characteristic that has previously been associatively tied to another can reawaken their link. Husserl writes, "The word 'sign' in our definition is to be taken in the widest conceivable sense" (Hua XII, p. 340/1994d, p. 20). For example if, after having lost my cup the week before, I were to walk into my favorite café, and see someone who is drinking out of a coffee mug with the same image of the Ouroboros on it, this presentation could arouse the associative link. The image on the cup would serve as a motivating sign, which passively impels me to recognize the signified authentically presented cup as mine.

Husserl's description of the second operation of linguistic signs-namely, to motivate me to present a surrogate that inauthentically presents the signifiedderives from his understanding of the function and purpose of thought. He states that thinking can be divided into higher- and lower-level psychological activities. Higher activities are those that are more difficult to execute-that is, they require more strenuous mental effort-whereas the lower-level performances are easier. ${ }^{8}$ The significance of this division comes to the fore when Husserl states that thinking is oriented towards expending less mental energy: thought has the telos of becoming more efficient (Hua XII, p. 353/1994d, p. 31). The lower-level activities are therefore preferred to the higher, as they are less demanding (Cf. Parpan 1984, Chapter 1).

Inauthentic presentations comprise one way that this goal of economized thinking can be achieved. For these presentations to occur, another associative link must be established subsequent to the institution of the tie between the coffee cup and linguistic sign that occurs when I first see the gift. With regard to the direction of my interest at the time, I passively construct a presentation that is a poor facsimile of the cup itself, that is, one that requires significantly less mental energy to be executed. This simpler presentation-for instance, of a blue circle (not an idealization, but an imagined sketch)—is then also associatively tied to the word "cup". The institution

\footnotetext{
8 Some examples of these higher and lower pairs are presentations in fantasy or sensation, presentations of more abstract or more concrete objects, presentations of relations or of absolute content, presentations of multiplicities or singularities, and presentations of psychical acts or objects (Hua XII, p. 352/1994d, p. 31).
} 
of this second tie promotes the efficiency of thought because, when I again hear that word, that link can be reawakened. Rather than being led to authentically present the coffee cup, which requires a great deal of mental effort, the link between the word and the simple presentation of the circle can be passively aroused. ${ }^{9}$

When presented, the circle serves as the surrogate for the cup: it replaces the latter. The circle functions as a second sign (in addition to the associatively motivating linguistic sign), which inauthentically presents (via replacement) the coffee cup. By being motivated to present the circle instead of the cup, I not only correctly grasp the pertinent characteristic of the signified object, but also expend less mental energy (Hua XII, pp. 354-355/1994d, pp. 33-35).

\subsection{Psychological and Logical Investigation of Surrogates}

While the above analysis exhausts Husserl's explicit discussion regarding the operation of surrogates in most of his early work, his closer examination in LZ makes it evident that such an investigation is insufficient. It is only stated that, but not explained how, the circle is able to inauthentically present the cup. Since Husserl recognizes that his philosophical account is incomplete, he executes a twostep examination of surrogative signs in LZ. First, he performs a psychological study which investigates the way surrogates arise and function. In a subsequent logical examination, Husserl analyzes how one can trust the result of judgments that utilize surrogates.

Husserl straightforwardly addresses the psychological task, disclosing that the circle replaces the coffee cup when I experience the former as the latter. He writes:

And so perfectly and assuredly do the signs surrogate for the actually intended concept that, in the majority of cases, we truly do not notice the distinction despite the tremendous gap [ungeheures Abstandes] between them. The signs and the rudiments represent the actually intended concept; however, we do not notice that they do this (Hua XII, p. 352/1994d, p. 31).

Here Husserl holds that the surrogates function so well as replacements that I normally do not notice that they are surrogates at all. When dealing with the circle, I take myself to be presented with the cup. Thus the surrogation of the circle for the cup is, according to the schema Husserl has devised, to be defined as a kind of misidentification. The presentation of the circle can provide me with the correct answer to my inquiry about the color of the cup because I have "confused" the former with the latter.

Husserl clarifies how I come to a correct understanding by means of inauthentic presentations by assigning variables to the mental correlates of the replacement

\footnotetext{
9 Concerning this replacement process Husserl, in LZ, uses the example where the presentation of the word "sphere" associatively guides me to a presentation of a ball, which functions as the sphere's surrogate (Hua XII, p. 353/1994d, p. 33). I have chosen instead to use the example of the circle surrogating for the coffee cup because the case where the ball replaces the sphere is quite complex, since it concerns a genetically primary and principally necessary surrogate. Only after the analysis, in Sect. 2.2 below, of these kinds of inauthentic presentations could the ball and sphere example be properly explicated.
} 
experience. When applied to my example, the cup is to be labeled as $\mathrm{G}$, the circle as $\mathrm{X}$, and the blue color as $\alpha$. With this in mind, it is possible to understand what Husserl means when he writes, "A judgment is tied exclusively to $\mathrm{X}$, provided that it possess feature $\alpha$; G possesses feature $\alpha$; thus, the judgment is also valid of $G$ in this regard" (Hua XII, p. 352/1994d, p. 32). Because I mistake the blue color of the circle $(\mathrm{X} \alpha)$ for the blue color of the cup $(\mathrm{G} \alpha)$, I "correctly" judge that the latter is so colored. The presentation of the cup $(\mathrm{X} \alpha)$ can serve as an appropriate replacement because it also possesses the single feature pertinent here, the blue property $(\alpha)$, which I take as being presented of the coffee mug $(\mathrm{G})$. In this case I have no-and according to Husserl, need no-authentic presentation of the cup to accurately answer my friend's question, since the surrogate provides me with the pertinent information concerning the color.

This mistaking or inauthentic presenting is possible because of the passive reawakening of the surrogate. With regard to my interest ${ }^{10}$ in the color of the cup, my passive consciousness switches out one object for another for the sake of saving mental energy — or, more appropriately, allows for the execution of one presentation rather than another. As I am not actively aware of the replacement, I can take the object presented before me as the cup, rather than as the circle that it is. ${ }^{11}$

Turning now to his logical examination, Husserl seeks to explain how linguistic surrogates operate reliably. He believes that most of our thinking is executed by means of replacements and, moreover, that in the vast majority of cases these

\footnotetext{
${ }^{10}$ Husserl emphasizes that it is the direction of my interest that serves as referee for the replacement process. Depending upon my interests at the moment, the same presentation can serve as a surrogate for distinct signified objects, and the same intentional object can be inauthentically presented via different replacements (Hua XII, p. 353/1994d, p. 32).

${ }^{11}$ As it is easy to miss the radical nature of this doctrine of surrogates by reading LU back into LZ, three preemptive comments concerning the relationship between the two texts are necessary. The reader should keep these in mind while reading Sect. 3 below. First, a surrogate does not function like any of the cases in Sect. 18 of the First Investigation, where Husserl calls them a "foothold for the intellectio [Anhalt für die intellectio]" (Hua XIX, p. 70/1970, p. 208). He introduces a line drawn on a chalkboard as one such foothold for the awareness of an ideal straight line. The intuition of this sketched line does not present me with the concept or meaning of a straight line, but rather serves as the "natural starting point for geometrical idealization" (Hua XIX, p. 70/1970, p. 208). According to the Husserl of 1890, if the drawn line served as a surrogate for an ideal straight line, my mistaking of the former for the latter would, in contrast, be the end point of this experience. When experiencing an inauthentic presentation, I am not, as is the case with motivating signs, impelled to authentically present the signified object. Second, the fact that the surrogate can appear "instantaneously" (blitzschnell) (Hua XII, p. 353/1994d, p. 32) and then disappear just as quickly does not contravene the first point just laid out. The surrogate would still provide me with all of the information pertinent to my interest, despite its limited appearance. In LU, Husserl explicitly criticizes this doctrine from LZ, writing, "If one claimed that phantasy operates in these cases, but in an exceptionally transitory manner [in großer Flüchtigkeit], such that an image appears, only immediately to disappear, then we answer that, as the complete understanding of the expressions, their complete, living sense, can still persist after the images have vanished, the understanding of the expressions cannot persist in these images" (Hua XIX, p. 69/1970, p. 207). Finally, surrogates are not entirely similar to the "analogical intuitions" Husserl describes in Sect. 52 of the Sixth Investigation. While they function in very similar manners, that which is analogically intuited is presented-so states Husserl in 1901-in full knowledge of the fact that I am not given the signified in that experience (Hua XIX, pp. 690-693/1970, pp. 292-294).
} 
surrogates do allow us to accurately comprehend the object of interest. ${ }^{12}$ This is not merely happenstance. Surrogates operate in a dependable manner because there is some mechanism that ensures their trustworthiness. Simply stated, Husserl's logical investigation in LZ is dedicated to discovering this guarantor.

The problem Husserl identifies concerns not the surrogates themselves, but that which allows for the consciousness of them: the motivating operation of the linguistic sign. He explains that when I perceive this sign, it arouses the presentation of the surrogate by means of the blind psychological mechanism of association (Hua XII, p. 358/1994d, p. 37). Since this reawakening occurs passively, it is not rationally controlled, and so it seems likely that I would be motivated by the sign to execute presentations that would not allow me to correctly understand the object of my concern. He explains, "It is truly and a priori possible for one to entertain the thought that the psychological equipment of our nature should impel our practical (extralogical) judgments always or predominantly to error and only occasionally to truth" (Hua XII, p. 358/1994d, p. 37). While the direction of interest does serve as a partial restraint, Husserl believes that this cannot fully account for the "metaphysically very interesting fact [eine metaphysisch sehr interessante Tatsache]" that surrogates operate in a dependable manner (Hua XII, p. 358/1994d, p. 37).

While the associative connection between the linguistic sign and the surrogate introduces a certain randomness, Husserl can explain the reliability of the surrogative experience by turning to the relationship between the replacement and the replaced. It is the latter connection that serves as the check upon the former; it reins in the unpredictability of the linguistic sign's passive motivation. A requirement must be met for one presented object to serve as the replacement for another. The surrogate must be "a rough approximation [eine grobe Annäherung]" (Hua XII, p. 353/1994d, p. 32), or within a certain range of similarity, of the replaced object with regards to the direction of my interest. Because I am concerned with the color of the cup, the blue color of the circle has to be roughly the same as that of the cup if it is to serve as its surrogate. There are thus a great many objects that could function as a replacement for the coffee cup, so long as they were within the pertinent range of approximation.

Husserl asserts that this serves as a check on the linguistic sign's motivating operation because he believes that when the surrogates are not within this degree of similarity, "the symbols do not fulfill their purpose, the flow of thought stops, and we note to ourselves that we are lacking the true concepts" (Hua XII, p. 353/1994d, p. 32). If the linguistic sign arouses a surrogate that is not within the range of affinity with the replaced, then that surrogate cannot perform its function.

If the sign "cup" motivated me to execute a presentation of a red circle instead of the blue one, then because this red circle does not approximate the coffee cup's color, Husserl holds that I would recognize the difference between them. ${ }^{13}$ This

\footnotetext{
12 "For the most part, we do quite well when we judge by utilizing surrogates (and the vast majority of all of our judgments are of this kind)" (Hua XII, p. 358/1994d, p. 37).

13 To be clear, the red circle cannot serve as a surrogate for the coffee cup in this case because I am only interested in the color of the latter. If I were interested in determining the shape of the lid of the cup, the red circle may function as a perfectly fine replacement, since it can disclose to me the relevant information (that the lid is circular). The range of approximation is thus only restricted in accordance with my interests at the time.
} 
surrogate cannot be mistaken for, or inauthentically present, the cup since their colors significantly diverge. My "thought stops" and I see the red circle as an inappropriate replacement. As a result, I do not take the world in an incorrect way; I do not think that the cup is red nor do I respond erroneously to my friend's question concerning the color. As I can no longer utilize this presentation as a surrogate, I instead authentically present the coffee cup by perceiving it, which, despite requiring more mental energy, allows me to correctly know its color. ${ }^{14}$

\subsection{Differentiation of Surrogates}

Husserl realizes that replacements can be formed and function in several different manners, so he is not content to provide just this overarching exposition of how all surrogates operate and operate reliably. He works from these conclusions so as to augment his semiotics by differentiating replacements on the basis of their genetic origins and degrees of necessity. His divisions can be charted as follows.

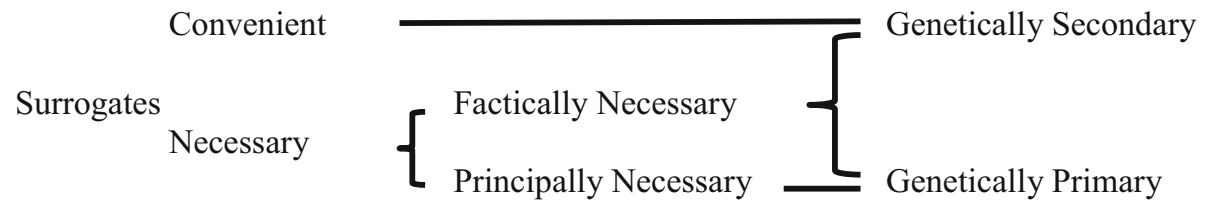

Husserl begins with the distinction between convenient (Hua XII, pp. 351-354/ 1994d, pp. 30-33) and necessary (Hua XII, pp. 354-357/1994d, pp. 33-36) surrogates, which concerns whether or not the object that is replaced can be authentically presented. When the circle replaces the cup, it is possible for me, by means of reflection, to recognize that I am dealing with a surrogate. In the case where the coffee cup is sitting on the table before me, I can reawaken the associative link between the word and the coffee cup itself. I can once more perceive the cup so as to correctly answer the question my friend has asked about its color. This is to say that it is convenient for me to present the circle-replacement, as I save mental energy by doing so, but it is not necessary. Husserl thus defines convenient surrogates as those replacements whose replaced objects can, at that moment, be authentically given.

Necessary surrogates, in contrast, do not allow for this shift to authentic presentation. This restriction can be in place for two different reasons. On the one hand, the authentic presentation of the signified object may be factically denied to

\footnotetext{
${ }^{14}$ Here we should note a serious problem with Husserl's explication. I could only know that the color of the circle was unlike the color of the coffee cup by having both presented to me and then comparing or contrasting them. If Husserl had recognized this point, he would also have seen that his theory collapses. Recall that the reason why I utilize a surrogate is to save mental energy. Yet, since both the replacement and replaced would have to be given for the (reliable) functioning of the surrogate, it is clear that the surrogative process would actually require more mental energy than that of a simple authentic presentation. Instead of presenting the surrogate and the referent and then checking the former against the latter, my thinking would be more efficient, and I could still correctly know the signified object, by performing an authentic presentation. While it is important to recognize that Husserl's description of surrogates is flawed, this in no way changes the fact that this 1890 theory serves as the groundwork and inspiration for the First Investigation, as we shall show below.
} 
me (Hua XII, pp. 354-355/1994d, pp. 33-34). I am incapable of being presented with that object because of the particular situation or place I find myself in: I must, at this present time, utilize a surrogate to stand in for the signified. When I am out of perceptual range of my coffee cup, for example, the circle-surrogate (or any other replacement sign for the cup) would be factically necessary. On the other hand, surrogates that are principally or eternally necessary are those that have, regardless of circumstances, signified objects that can never be given authentically. Husserl cites the cases of God and the souls of others (Hua XII, p. 356/1994d, p. 35) as the clearest examples of principally necessary surrogates.

The third pertinent division, which cuts across the other two, concerns whether the replacement is constituted before or after I have been authentically presented with the to-be-signified object. The replacement of the coffee cup, as I have explained it, is an example of a genetically secondary surrogate (Hua XII, p. 354/ 1994d, p. 33). It was when I first saw the coffee cup that my consciousness then constituted the simpler or lower-level replacement (see note 7 above). It is possible for a genetically secondary surrogate to be convenient or factically necessary.

For genetically primary replacements (Hua XII, pp. 354-356/1994d, pp. 33-36), the situation is reversed. I constitute the surrogate before or without the possibility of the authentic presentation of the signified, and for this reason these replacements cannot be convenient. Such a formation process; however, seems inconceivable according to the schema Husserl has established. We know that the circle-surrogate was constituted by my passive consciousness as an energy-saving approximation of the coffee cup. As such, it also seems that if I were not first authentically presented with the cup, there would then be no model from which the surrogate could be created as a poor facsimile.

To explain Husserl's reasons for believing that the constitution of the surrogate can occur in a genetically primary manner, I apply his analysis to an example. Let us assume that one of my friends has come back from Chile after having discovered a new animal species, which he has termed, "Threshdohr". He has no pictures of this creature and I am therefore left to rely on his descriptions to comprehend what this animal looks like. In his explanation, my friend tells me about some of the animal's features, such as the fact that it is red, has horns, and its feet are hooved. Husserl writes that when this happens,

[t]hese single features are given; their groupings and interrelations are easily produced in phantasy according to familiar templates and the presentation of a something, which is similar to the formed phantasm, functions as a satisfactory replacement for the thing. If it happens that the replaced thing is then presented to me, it is possible for me to recognize it (Hua XII, p. 355/ 1994d, p. 34).

Husserl is stating that although I have not yet perceived the Threshdohr, I can imagine an object to serve as its surrogate. However, not just any image can perform this function. The replacement I fashion is one that I take to be similar to the Threshdohr on the basis of my friend's description. It can be a surrogate since it is ostensibly within the range of approximation of an actual Threshdohr. This formation occurs in several stages. First, as the characteristics (hooved, horned, and 
red), which my friend mentions to me, are familiar, I can present them in phantasy. These features are first separately given and then cohere into one presentation of what I imagine a Threshdohr to look like. The united imaginary presentation can then be associatively linked to, and serve as the surrogate for, the actual Threshdohr: When someone says that word again, the associative tie is aroused and I present that replacing image. This process becomes more complicated when Husserl explains that one further step normally occurs. He writes:

If we are sufficiently familiar with content-rich symbol-presentations which arise in this manner, then there ensues immediately a surrogation of these symbol-presentations by means of a convenient replacement presentation, which is poorer in content or even external. Thereby, we have a symbolization of the second order. And this is correspondent to the repeatedly mentioned economic pull of our Geist (Hua XII, p. 355/1994d, p. 34).

In this quote, which demonstrates well the tortuous manner in which Husserl composes his insights in LZ, he is claiming that my consciousness may not be content with the first surrogate I have constituted, because it is very rich in detail. As a result of the energy-saving tendency of consciousness, I normally come to passively formulate a second replacement that is poorer in content and requires less exertion on my part than the first. This second surrogate, which may perhaps be just the outline of a bull that is colored in red, is then associatively tied to the word, "Threshdohr", such that it can serve as its replacement when I come upon that word in speech or writing once more.

Finally, this genetically primary surrogate is to be classified as factically inaccessible, rather than principally so because I can go and see the animal in Chile. If I did, and if I had formed an appropriate surrogate, then the creature would resemble the replacement such that I could recognize it as a Threshdohr. If, in contrast, I had created an improper surrogate, the difference between the replacement and the animal would make the latter unidentifiable. In this case, if someone told me that the creature that I see is a Threshdohr, my previous replacement would be abandoned and I could form a new more accurate genetically secondary surrogate.

\section{The Semiotics of Logical Investigations}

With this understanding of Husserl's theory of surrogates from LZ in mind, it may appear evident to those familiar with his First Logical Investigation that the latter is an unequivocal rejection and not a revision of the former. This conclusion is temping because, in that 1901 work, Husserl only dedicates one section (Hua XIX, pp. 73-75/1970, pp. 210-211) to discussing surrogates in detail, within which he straightforwardly asserts that no sign ever operates as a replacement. He writes, "It is a very inappropriate description of the state of affairs, if one has spoken of a substitutional function of the signs, as if the sign itself surrogates for something else and as if our interest in symbolic thinking would be directed to the signs themselves" (Hua XIX, p. 73/1970, p. 210). 
While it is certainly the case that Husserl abandons the idea of surrogates in 1901 (and in most respects, already by 1894), ${ }^{15}$ it will be shown that he does so by preserving the overarching schema of signitive experience he established in 1890 . Further, he adopts and revises his previous theory of motivating signs by bifurcating, while simultaneously narrowing, the associative function of such signs. He still states that words and sentences can motivate me to execute one of two experiences. Instead of writing that I can be impelled to perform authentic or inauthentic presentations, Husserl now claims that linguistic signs can motivate me to execute intuitive or empty meaning-intentions. ${ }^{16}$

To begin with the former revision, we remember that Husserl stated in LZ that not only linguistic signs can perform a signitive function, but also that any object or characteristic of an object that has an associative tie with another may do so, if or when that tie is reawakened. He recognizes in 1901 that this understanding was too broad: He sees that the two-step operation of association or motivation is responsible for a great number of conscious experiences, ${ }^{17}$ only a few of which should be classified as signitive. While he will maintain that signs can function by means of association, the initial goal of his First Logical Investigation is to strictly delimit which associative connections are also signitive relations. Specifically, he states that there are two experiences that can be so classified, those where a sign indicates, and those where it motivates me to execute a meaning-intention.

To present Husserl's analysis of indicating signs (Hua XIX, pp. 30-37/1970, pp. 183-187), I examine his conclusions through the lens of the classical example of indication-namely, where smoke indicates fire. The distinguishing feature of an experience that allows Husserl to classify it as indicative and thus signitive, instead of merely associative, is that the presentation of one object or characteristic, which is given as existing in reality, arouses an associative tie that motivates me to become aware of the reality of another object or characteristic. If this connection between the smoke and the fire were only associative, when I see the latter I would only be impelled to have an awareness of the former. But such an experience can also be

\footnotetext{
15 To be emphasized: Husserl's thought did not undergo a radical shift in 1901 , as if he immediately jumped away from his 1890 theory of surrogates at that later date. Instead, as is always the case with Husserl, his philosophy evolved slowly over time. The following juxtaposition of these two works is a presentation of the results of Husserl's decade-long endeavor to attain clarity with regards to signitive experience. I refer the reader to two texts in particular, within which Husserl's new philosophy of signification, as a reaction to LZ and also PA, began to crystalize: "Anschauung und Repräsentationen. zur Klassifikation der Repräsentationen (1893-1894)” (Hua XII, pp. 406-11/1994b, pp. 452-458), and, "Psychologische Studien zur elementaren Logik (1894)" (Hua XXII, pp. 92-123/1994e, pp. 139-170). For further information on the gradual transformation of Husserl's philosophy during this time, see Schuhmann (1990).

16 In his unpublished dissertation, Micah Tillman (2011) also explains how Husserl reformulates authentic and inauthentic presentations into intuitive and empty intentions. However, his descriptions never extensively draw from LZ.

17 "To form that which belongs together from that which is merely co-existent-or more precisely: to form from mere co-existence an intentional unity, which belongs together-, that is the continual psychological contribution of the associative function. All experiential unities, as empirical unities of things, of events, or of thingly orders and relations is a phenomenological unity by means of the felt mutual belongingness of the parts and sides of the appearing object, which can stand out as units" (Hua XIX, p. 36/1970, p. 187, emphasis mine).
} 
indicative, because the smoke (indicating sign), which is presented as really existing, motivates and gives good evidence for my belief in the reality of the fire (indicated and signified state of affairs). Husserl writes that the indicating object, "not merely recalls another object and in this way points to it; rather, it also provides evidence for that other object. It fosters the acceptance of the fact that it likewise exists" (Hua XIX, p. 37/1970, p. 187).

The other experiences that Husserl states are of a signitive character are those that can be ranked under the heading of expression (Hua XIX, pp. 37-110/1970, pp. 187-233). All expressive signs are necessarily linguistic, that is, they consist of words or sentences. These expressive linguistic signs have two functions, one of which occurs by means of association, while the other does not. The associative function is operative when I experience language from the perspective of the listener or reader. The experience of certain linguistic signs is associatively tied to a sense- or meaning-giving intention, such that when I once more see or hear the former (as the listener or reader), I am motivated to execute the latter. Husserl writes: "The function of a word (or rather of an intuitive word-presentation) is to awaken a sense-conferring act in ourselves" (Hua XIX, p. 46/1970, p. 193).

Husserl lists three characteristics of expressive signs that distinguishes them from indicative and merely associative signs. In contrast to indication, the existence of the word does not provide motivation for a belief in the reality of the signified. When I read the word Jupiter, I do not have grounds to believe that the King of the Olympian Gods exists. ${ }^{18}$ Moreover, neither the words (as when I imagine them) nor the signified (as in the case of Jupiter) have to exist at all (Hua XIX, pp. 41-43/ 1970, pp. 190-191). The second requirement for a sign to be an expression is that it not only possess a grammatical structure, but, as is explained in further detail in the Fourth Investigation, a structure that mirrors that of the meaning and of the signified state of affairs. An isomorphism must obtain between the expression and the signified. ${ }^{19}$ The third distinction is that someone must give these expressive signs sense via a meaning-giving act. It is this endowment that allows for the sign's second function, which will now be examined. ${ }^{20}$

\footnotetext{
18 "The being of the sign does not motivate the being, or more precisely, our conviction of the being of the meaning. What serves as an indication must then be perceived as existent [...] The non-existence of the word does not disturb us. Moreover, this non-existence also does not interest us. The function of the expression as an expression in no way depends on the existence of the sign" (Hua XIX, pp. 42-43/1970, p. 191).

19 "It is clear: If 'authentic' presentations are to be mirrored truly in the sphere of the meaning-intentions of 'symbolic' presentations, then it must be the case, as it is so a priori, that each form on the side of presentations, which can potentially undergo fulfillment, corresponds to a form on the meaning side of the intention. And if it should also be the case that speech in its verbal material truly mirrors all a priori possible meanings, then language must have at its command grammatical forms which give distinguishable expression to all of the distinguishable forms of meaning" (Hua XIX, p. 313/1970, p. 55). For further discussion on the isomorphism established in the Fourth Investigation, see Bar-Hillel (1957), Drummond (2002, 2003), Edie (1972) and Sokolowski (1968).

${ }^{20}$ While Husserl only briefly discusses what I have called the first or associative function of words in LU, he does dedicate great efforts to examining it in his revisions to the Sixth Logical Investigation from 1913/14 (Hua XX/1-2). He there details how, when I see the word, an impersonal "should" (Sollen) is placed upon me to execute the meaning intention. He writes, "We can also say: The habitual sign is a carrier of a practical demand, and truly an impersonal demand, which is no longer the conscious
} 
The division between Husserl's description of the first and second operation of expression is often portrayed as a distinction between which perspective is assumed - that of the speaker or of the listener (or between a noetic or a noematic investigation of meaning) (Bernet et al. 1993, pp. 170-180). Instead, it should be understood that the listener experiences both functions, while the speaker only the second. When I (as a listener) see the linguistic signs, we know that the words perform their associative operation by passively motivating me to execute the meaning-giving intention. Husserl states that this latter intention then fuses with the act that constitutes the words (Hua XIX, pp. 35-51/1970, pp. 187-194). The senseintention endows the words ${ }^{21}$ with the meaning, such that the signs execute their second function: they now mean and signify their referent. Husserl writes, "In virtue of the $<$ meaning $>$ acts, the expression is more than a merely sounded word. It means something, and by means of the fact that it means something, it relates to the object" (Hua XIX, p. 44/1970, p. 192). Husserl claims that the speaker or writer only ever experiences this second meaning-operation of the signs, and this assertion is founded in his belief that there can be non-linguistic thoughts and judgments. The speaker can first execute a meaning-giving act and then "choose" the words appropriate to express that meaning (see Rolf 2003; Sebestik 2003). Because the already-constituted meaning links itself to the words, this eliminates the possibility that the words could associatively motivate me to execute a meaning-act.

The more prodigious revision Husserl makes to his semiotics in 1901 concerns the kinds of presentation which linguistic or expressive signs can motivate me to perform. Instead of authentic and inauthentic presentations, Husserl states in LU that expressions can impel me to execute intuitive or empty meaning-intentions, where the latter dyad parallels the former. He thereby modifies his thought in two distinct ways. First, Husserl only lightly revises his notion of authentic presentations so as to develop his description of intuitive meaning-acts. In stark contrast, he completely abandons the idea that signs can be replacements, and he does so by claiming that I can meaningfully intend objects which are not authentically or intuitively given to me, via empty intentions.

To first discuss the less drastic alteration, Husserl states in both 1890 and 1901 that an experience falls under the respective heading of authentic or intuitive when its object is given to me in a sensorial, that is, in a perceptual or imaginative manner. Both kinds of presentation lay before me an object in full phantasorial or memorial givenness. Moreover, he claims that authentic or intuitive acts may be simple, as when I am associatively motivated by a name (Hua XII, p. 341/1994d, p. 21; Hua XIX, pp. 476-484/1970, pp. 147-151, Vol. II) or they can be intellectually formed, for example, when I read a sentence (Hua XII, pp. 342-344/1994d, pp. 22-23; Hua XIX, pp. 657-734/1970, pp. 269-319, Vol. II; see note 5 above). According to the

Footnote 20 continued

realization of previous willing. Instead of me commanding myself or someone else commanding me, it is the sign which so commands me, and it commands me purely in and of itself and not as a correlate of a personal demand" (Hua XX/2, p. 86).

21 Correctly stated, before a meaning-intention lends the words their meaning, they are not words but rather physical scribbles on a page or noises that one can hear. Only once the scribble or sound has been given its meaning can it be called a word or expression. 
Husserl of both LZ and LU, it is the case that I can be associatively impelled by the linguistic sign, "cup", to present the coffee cup, and this experience is what determines, albeit in the different ways described above, the meaning of that name.

Concerning his other modification, Husserl introduces the notion of empty intentions in 1901 because he now recognizes that his descriptions of surrogates were misguided. He sees that he was actually taking the process of inauthentic presentation as occurring, in part, by means of imagination. According to that 1890 schema, I am able to execute an inauthentic presentation of the coffee cup by imaginatively presenting the circle. He claimed that it is because the circle-image is within the pertinent range of similarity (with regard to my interest) to the cup, that I am able to mistake the former for the latter and thereby meaningfully intend the coffee cup itself. This is to say that Husserl described those cases where I am not authentically given the object, but yet mean it, by establishing and applying an image-theory of meaning: I can inauthentically present the coffee cup by imagining the circle, which is confused for the cup. The image serves as the meaning of the absent cup.

Husserl emphatically rejects this idea in 1901, as he sees that meanings are never images, nor are meaning-intentions necessarily accompanied by imaginative acts even in those cases where I am not intuitively given the object. Expressing this in most caustic language, he writes:

It is proof of the retarded state of descriptive psychology that such obviously specious doctrines should be entertained, and entertained despite long standing objections urged against them by unprejudiced observers. Certainly, in many cases linguistic expressions are accompanied by phantasy-presentations, which stand in a closer or further relationship to the meaning; however, it is counter to the plainest fact, that such an accompaniment is everywhere a necessary condition for understanding. With this is simultaneously stated, that the meaningfulness of an expression (and indeed the meaning itself) cannot consists in the existence of such images and cannot be disturbed by their absence (Hua XIX, pp. 67-68/1970, p. 206).

As a result of this recognition, Husserl develops his philosophy of empty intentions by contrasting it to such an image-theory. To be highlighted is that he is still trying to account for the "same" experiences: He is seeking to understand how I can mean an object that is not intuitively or authentically presented. Yet, if images do not stand in for the absent objects, then there seems to be no way in which I could signify them. In his ingeniously simple resolution to this difficulty, Husserl states that I can and often do meaningfully experience such objects precisely because a meaning-act can also be directed to objects that are not intuitively given. By executing an empty meaning-intention, I can be conscious of an object which is not sensorially present and, in fact, may not even exist (Hua XIX, pp. 67-82/1970, pp. 206-215). When I emptily express, "coffee cup", it is my non-intuitive awareness of that object (and not some imaginative presentation of the cup or of a similar image) that endows the name with its meaning.

Further clarity concerning Husserl's semiotics in 1890 will help to reveal the pertinent contrast between the two works. Even though imagination is responsible 
for providing the surrogate in the above case, it is not the only kind of experience that could do so. The perception of a blue circle on a chalkboard, for example, would equally serve to present a replacement. In fact, any kind of intuitive experience Husserl identifies in LU could be said to constitute a surrogate, as the latter is conceived in LZ. If we understand "images" in an extended sense, as any intuitively presented object, it would still be correct to characterize Husserl's philosophy of signitive experience as an image-theory. If taken in a narrow sense, such that images mean only the correlates of imagination, then Husserl's 1890 semiotics could more appropriately be classified as an intuitive-theory of meaning: for the early Husserl, all meanings and objects, be they intended via authentic or inauthentic presentations, are actually given via intuitions. In the case of authentic presentations, the signified object is obviously intuitively intended. During inauthentic presentations, the surrogate is also given to me in an intuition, albeit a mistaken one. The inauthentic presentation can by no means be classified as an empty intending, but rather as an incorrect intuitive presentation, where I confuse the intuitive replacement for the absent replaced.

Husserl asserts in LZ that authentic and inauthentic presentations are the only two kinds of experience that can constitute an object (Hua XII, p. 340/1994d, p. 20), and since both are intuitive, it is evident that he had no account of empty intentions in 1890. Even though Husserl does recognize that I can intend objects not directly presented or even presentable, a close examination of his descriptions makes it clear that these intentions are in fact just another kind of experience of presence. He is unable to see how I could be meaningfully directed at an intentional object when that object or some approximation of it is not intuitively given to me. Because I can only ever execute intuitive intentions, even when I begin to think, my consciousness is composed of an unbroken stream of intuitions; being bombarded by presence, there is no hint of absence. ${ }^{22}$

Husserl's definitive rejection of his previous conclusion-that consciousness is invariably confronted with presence-reveals that he is not one who has, as one gravely misguided philosopher claimed, "an obstinate desire to save presence" (Derrida 1967/2011, p. 57/43), but in fact the opposite (cf. Crowell 1996, Hopkins 1985). By recognizing that one can intend absent objects and states of affairs without requiring some other form of presence, and by describing how I can mean the same object in either an intuitive or empty manner, Husserl is ultimately affirming that consciousness' relation to absence is constitutive of its relation to presence. ${ }^{23}$ It has been a central purpose of this paper to disclose this reversal in Husserl's thought, which is the result of a decade of arduous research. On the other hand, and perhaps more importantly, I have tried to demonstrate that the transformation of this tenet, where Husserl comes to correctly appreciate the principality of absence, could only have occurred within the larger context of the

\footnotetext{
22 With regard to this point, Husserl is clearly under the influence not only of Brentano, but also Alexius Meinong. As I am unable to discuss the significant, but also contentious relationship between Husserl and Meinong, I refer the reader to Ierna (2009), Rollinger (1993, 2004, 2009), and Schubert and Luise (1978).

23 Working from this insight of the First Investigation, Husserl will even go on in the Fifth and Sixth to assert that empty meaning intentions are those that primarily and always endow an expression with its meaning (Hua XIX, pp. 570-572/1970, pp. 209-210, Vol. II).
} 
development of his 1901 philosophy of meaning intentions-not as a rejection but rather as a revision of his 1890 semiotics. $^{24}$

Acknowledgements I would like to thank Ullrich Melle, Julia Jansen, Carlo Ierna, Diego D’Angelo, and Claudio Majolino for their most helpful comments on this essay.

\section{References}

Bar-Hillel, Y. (1957). Husserl's conception of a purely logical grammar. Philosophy and Phenomenological Research, 17(3), 362-369.

Bernet, R., Marbach, E., \& Kern, I. (1993). An introduction to husserlian phenomenology. Evanston: Northwestern.

Byrne, T. (Forthcoming). Husserl's early semiotics and number signs: Philosophy of Arithmetic through the lens of "On the Logic of Signs (Semiotic)". Journal of the British Society for Phenomenology.

Crowell, S. (1996). Husserl, Derrida, and the phenomenology of expression. Philosophy Today, 40(1), 61-70.

D'Angelo, D. (2013). The foundations of alterity. Husserl on referencing and indicating. Investigaciones Fenomenológicas, 10, 53-71.

Derrida, J. (1967). La voix et le phénomènen. Paris: Presses Universitaires de France. Voice and Phenomena L. Lawlor (Trans.). Evanston: Northwestern 2011.

Drummond, J. (2002). The Logical Investigations: Paving the way to a transcendental logic. In D. Zahavi \& F. Stjernfelt (Eds.), One hundred years of phenomenology: Husserl's Logical investigations reconsidered (pp. 31-40). Dordrecht: Springer.

Drummond, J. (2003). Pure logical grammar: Anticipatory categoriality and articulated categoriality. International Journal of Philosophical Studies, 11(2), 125-139.

Edie, J. (1972). Husserl's conception of "the grammatical" and contemporary linguistics. In L. Embree (Ed.), Life-world and consciousness (pp. 137-161). Evanston: Northwestern.

Hopkins, B. (1985). Derrida's reading of Husserl in Speech and Phenomena: Ontologism and the metaphysics of presence. Husserl Studies, 2(2), 193-214.

Hopkins, B. (2002). Authentic and symbolic numbers in Husserl's Philosophy of Arithmetic. The New Yearbook for Phenomenology and Phenomenological Philosophy, 2, 39-71.

Hua XII. Husserl, E. (1970). Philosophie der Arithmetik. Mit ergänzenden Texten. L. Eley (Ed.), Den Haag: Martinus Nijhoff; Philosophy of arithmetic. Psychological and logical investigations with supplementary texts from 1887-1901 D. Willard (Trans.). New York: Springer 2003.

Hua XIX. Husserl, E. (1984). Logische Untersuchungen. Zweiter Teil. Untersuchungen zur Phänomenologie und Theorie der Erkenntnis. U. Panzer (Ed.). Den Haag: Martinus Nijhoff.

Hua XX-1. Husserl, E. (2002). Logische Untersuchungen. Ergänzungsband. Erster Teil. Entwürfe zur Umarbeitung der VI. Untersuchung und zur Vorrede für die Neuauflage der Logischen Untersuchungen. U. Melle (Ed.). Den Haag: Kluwer Publishers.

Hua XX-2. Husserl, E. (2005). Logische Untersuchungen. Ergänzungsband. Zweiter Teil. Texte für die Neufassung der VI. Untersuchung. Zur Phänomenologie des Ausdrucks und der Erkenntnis. U. Melle (Ed.). Den Haag: Kluwer Publishers.

Hua XXI. Husserl, E. (1983). Studien zur Arithmetik und Geometrie. Texte aus dem Nachlass. I. Strohmeyer (Ed.). Den Haag: Martinus Nijhoff.

Hua XXII. Husserl, E. (1979). Aufsätze und Rezensionen. B. Rang (Ed.). Den Haag: Martinus Nijhoff. Husserl, E. (1970). Logical investigations Vol. I and II. J. N. Findlay (Trans.). New York: Routledge.

Husserl, E. (1994a). Early writings in the philosophy of logic and mathematics. D. Willard (Trans.). New York: Springer.

\footnotetext{
${ }^{24}$ While this article has disclosed LZ as the palimpsest for the First Investigation, the 1890 text holds even further value for understanding the evolution of Husserl's thought. In my forthcoming work, "Husserl's early semiotics and number signs," I apply Husserl's analysis of signitive experience in LZ to his discussion of number signs in PA, which casts that seminal 1901 book in a new light. By placing the latter text in the context of the former, Husserl's conclusions concerning the authentic and inauthentic presentations of numbers via number signs, and his explanation of the genesis of and need for the number system, are clarified in novel ways.
} 
Husserl, E. (1994b). Intuition and Repräsention. towards a classification of Repräsentation. In Early writings in the philosophy of logic and arithmetic (pp. 452-458). D. Willard (Trans.). New York: Springer.

Husserl, E. (1994c). Letter from E. Husserl to Carl Stumpf. In Early writings in the philosophy of logic and arithmetic (pp. 12-19). D. Willard (Trans.). New York: Springer.

Husserl, E. (1994d). On a logic of signs (semiotic). In Early writings in the philosophy of logic and arithmetic (pp. 20-51). D. Willard (Trans.). New York: Springer.

Husserl, E. (1994e). Psychological studies in the elements of logic. In Early writings in the philosophy of logic and arithmetic (pp. 139-170). D. Willard (Trans.). New York: Springer.

Ierna, C. (2003). Husserl and the infinite. Studia Phaenomenologica, 1-2, 179-194.

Ierna, C. (2005). The beginnings of Husserl's philosophy, Part 1: From "Über den Begriff der Zahl” to Philosophie der Arithmetic. The New Yearbook for Phenomenology and Phenomenological Philosophy, 5, 1-56.

Ierna, C. (2009). Relations in the early works of Meinong and Husserl. Meinong Studies, 3, 7-36.

Majolino, C. (2010). Structure de l'indice et équivocité du signe. A l'origine du partage. Anzeige/ Ausdruck dans les 'Recherches logiques'. Histoire Épistémologie Langage, 32(2), 1-56.

Majolino, C. (2012). La fabrique du renvoi. Sur quelques thèmes sémiotiques chez le premier Husserl. In C. Majolino (Ed.), Sémiotique et phénoméologie (pp. 93-114). Paraddigmi: Franco Angeli.

Parpan, R. (1984). Zeichen und Bedeutung: Eine Untersuchung zu Edmund Husserls Theorie des Sprachzeichens. Diss. Ruper-Karl U.

Rolf, G. (2003). Bolzano and the problem of psychologism. In D. Fisette (Ed.), Husserl's logical investigations reconsidered (pp. 95-108). Dordrecht: Springer.

Rollinger, R. (1993). Meinong and Husserl on abstraction and universals: From Hume studies I to Logical Investigations II. Amsterdam: Rodopi.

Rollinger, R. (2004). Austrian theories of judgment: Bolzano, Brentano, Meinong, and Husserl. In A. Chrudzimski \& W. Huemer (Eds.), Phenomenology and analysis: Essays in central European philosophy (pp. 257-284). Frankfurt: Ontos Verlag.

Schubert, K., \& Luise, M. (1978). Alexius Meinong on objects of higher order and Husserl's phenomenology. Dordrecht: Springer.

Schuhmann, K. (1990). Husserl's doppelter Vorstellungsbegriff: Die Texte von 1893. Brentano Studies, 3, 119-136.

Sebestik, J. (2003). Husserl reader of Bolzano. In D. Fisette (Ed.), Husserl's logical investigations reconsidered (pp. 59-81). Dordrecht: Springer.

Sokolowski, R. (1968). The logic of parts and wholes in Husserl's Investigations. Philosophy and Phenomenological Research, 28(4), 537-553.

Tillman, M. (2011). Empty and filled intentions in Husserl's early work. Diss: Catholic University of America.

Willard, D. (1980). Husserl on a logic that failed. The Philosophical Review, 89(1), 46-64.

Zuh, D. (2008). How do categorial representations influence everyday intuition? On Husserl's early attempt to grasp the horizontal structure of consciousness. Studia Universitatis Babes Bolyai Philosophia, 12, 49-62.

Zuh, D. (2012). Wogegen wandte sich Husserl 1891? Ein Beitrag zur neueren Rezeption des Verhältnisses von Husserl und Frege. Husserl Studies, 28, 95-120. 